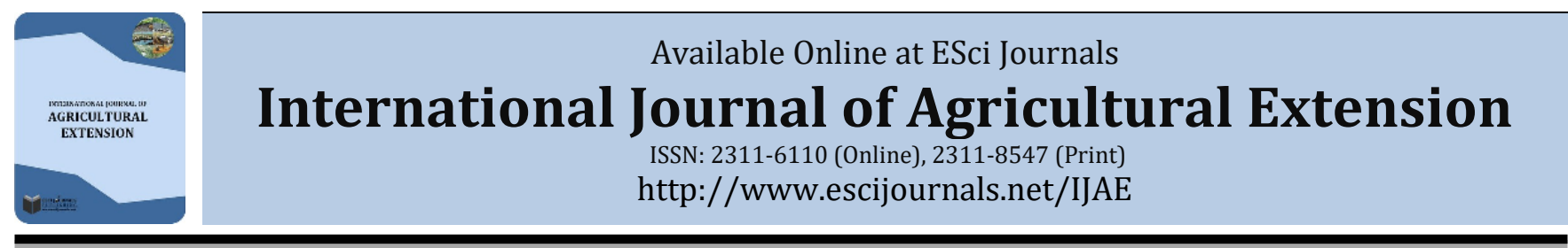

\title{
ASSESSMENT OF TRYPANOCIDAL DRUG RESISTANCE IN TSETSE INFESTED AREAS OF GURAFERDA DISTRICT, BENCH MAJI ZONE, SOUTH WESTERN ETHIOPIA
}

\author{
aAbiyu Tadele*, bTsegaye Teklemariam, bMulugeta Abera, cAyele Woldemeskel \\ a Department of Animal Science, Bonga University, Ethiopia. \\ ${ }^{b}$ Mizan Regional Veterinary Diagnostic Laboratory, Mizan Aman, Ethiopia. \\ ${ }^{c}$ Animal Product, Drug and Feed Quality Assessment Center, Addis Ababa, Ethiopia.
}

\section{A B S T R A C T}

The South Western region of Ethiopia is affected by both tsetse and non-tsetse transmitted trypanosomosis with a significant impact on livestock productivity. The control of trypanosomosis in Ethiopia relies on either curative or prophylactic treatment of animals with diminazene aceturate (DA) or isometamidium chloride (ISMM). This study was conducted from March - June 2017, where tsetse infestation was high in four purposively selected rural kebeles of Guraferda district of Bench Maji Zone, South Western Ethiopia. The main objective of this study was to assess trypanocidal drug resistance under natural grazing systems. Resistance to trypanocidal drug was determined through longitudinal studies. In this study 200 cattle were used for experiment; 50 cattle from each rural kebeles (25 treated and 25 control group). However, 16 animals 5 from control and 11 from threated group were left due to sale of the animals by the owners, refusal of owners to allow their animals during sample collection and inability to reach the study kebeles because of heavy rain and presence of mud. In the present study, 25 cattle were treated with isometamidium and 25 cattle were left untreated and examined regularly at two weeks interval for the presence of trypanosomes. During the experimental period, all infections were monitored in both groups and treated with diminazene $(7 \mathrm{mg} / \mathrm{kg}$ ) body weight. Resistance to isometamidium was assessed by comparing cumulative incidence in both treated and control group using the test relative risk reduction and deducting the rate of treatment failure. Resistance to diminizene was assessed through the rate of treatment failure observed at two week post treatment in the control group. In both cases the threshold of $25 \%$ treatment failure was adopted as criteria of presence of chemoresistance. The present study revealed that the prevalence of trypanosome infection was $(76.8 \%)$ in control and $(23.2 \%)$ in treated group. The trypanosome species in the area was predominantly due to T.Congolense (76.8\%). This indicates there was a resistance of trypanosome species for the treatment with the recommended dose of diaminazine $(7 \mathrm{mg} / \mathrm{kg})$ and isometamidium $(1 \mathrm{mg} / \mathrm{kg})$ body weight. Thus, it is crucial to develop an adequate prophylactic measurements to reduce the prevalence of trypanosome infection there by reducing tsetse fly populations in the study areas.

Keywords: Diminazene aceturate, Guraferda district, Hazard ratio, Isometamidium, Prevalence rate.

\section{INTRODUCTION}

Tsetse transmitted trypanosomiasis is a serious constraint to livestock production in sub humid and humid part of Africa including Ethiopia. Trypanosomiasis is responsible for the loss of about 3 million heads of cattle annually, where 50 million animals at risk in sub-Saharan Africa (Simbarashe et al., 2011). A total of 14.8 million cattle 6.12 million sheep and

* Corresponding Author:

Email: abiyu.tadele@yahoo.com

(C) 2019 ESci Journals Publishing. All rights reserved. and goat, 1 million camel, 1.23 million equines are at risk of contracting trypanosomiasis (Shimelis et al., 2005; Selamawi , 2016). In Ethiopia trypanosomosis is one of the important diseases which contribute to the direct and indirect economic losses on livestock production at least 6 million of the 31 million cattle of the country are exposed to the disease. The economic loss from the disease are decreased productivity and death of livestock. Apart from this direct economic loss, a vast area of arable land cannot be utilized for agricultural purposes due to fear of trypanosmosis (Zeleke, 2011). 
More over trypanosomiasis and its vector tsetse fly is a highly challenging problems in south west Ethiopia including Guraferda district of Bench Maji Zone. Infections from this contracting disease in domestic animals have always been an important production issue despite the struggle towards food security in the area. Economic losses are estimated to be high every year, low production of meat, milk, loss of traction power, mortality of the animals as well as the cost of trypanocidal treatment are the major causes of production losses in animals production (Dereje and Tesfa, 2017).

In most of sub-Saharan Africa, bovine trypanosomosis continues to be controlled primarily by trypanocidal drugs. Only three compounds isometamidium chloride, homidium (bromide and chloride) and diminazene acerurate are available for over 40 years (Ian et al., 2004). However the few drugs currently in use are in fear of with problem of efficacy, toxicity and or drug resistance as well as difficulties in administration. There are no new drugs being developed and of course no vaccine against trypanosomiasis has ever been or is likely to be developed (John, 2005). Accordingly high risk to the future use of the existing trypanocides is the development and spread of drug resistance to the point where they become in-effective over long areas of Africa to boot other existing risks.

Resistance to one or more of the trypanocidal drugs used in cattle has been increased due to misuse of the drug dose in most sub-Saharan Africa countries including Ethiopia (Bossche \& Connor, 2000; Solomon et al., 2016). Most of the currently available information on drug resistance was determined from case reports and doesn't give accurate information about the prevalence of resistance trypanosome in a region or a country. Very few surveys have been carried out using randomly selected trypanosomes isolates. In these few investigations that have been conducted on the existence of drug resistance which was found to be greater in those regions where drug use was more intensive. It was shown that resistance was wide spread in some regions of Africa where drug pressure is high enough to select resistant strains (Ian et al., 2004).

The herd owners in Guraferda district frequently treat their animals and at the same time facing high mortality due to trypanosome infection. In this particular area the Veterinary professionals as well as the farmers have been continuously reporting the death of animals with trypanosome infection. However, there was no previous studies conducted in isolating the presence of drug resistance with the available trypanocidal drugs. Thus, timely identification of the presence or absence of drug resistance was paramount importance to avert the existing problems and to generate a baseline information for policy makers at a regional or national level. Based on these background, this study was conducted in Bench Maji Zone Guraferda district in four selected kebeles to meet the following specific objectives.

- To assess the prevalence of trypanosome infection in the study area

- To assess the efficiency of isometamidium drug in the study area.

- To assess the presence of drug resistance trypanosomes in the study area.

\section{MATERIALS AND METHODS}

\section{Description of the study area}

Study area: This study was conducted in four rural kebeles of Guraferda district of Bench Maji Zone, South Western Ethiopia. The district is located between $34^{\circ} 55^{\prime} 59^{\prime \prime}$ to $35^{\circ} 26^{\prime} 13^{\prime \prime}$ E Latitude and $6^{\circ} 29^{\prime} 5^{\prime \prime}$ to $7^{\circ} 13^{\prime} 20^{\prime \prime}$ N Longitude. It covers an area of $228,281.25$ ha. Of these $126,725.98$ was supposed to be infected by tsetse and other mechanical trypanosomiasis transmitter flies. Guraferda district is bordered on the south by Bero district, on the west and north by the Gambela Region, on the northeast by Sheko district, on the east by South Bench district, and on the southeast by Menit Shasha district. The elevation ranges of the district lays between 559 and 2389 m.a.s.l. (Dejene et al., 2018). The agro-ecology of the area is potentially dominated by lowland representing $72 \%$ and the remaining $28 \%$ is midland. The annual rainfall varies from 1601-2000 mm whereas the mean annual rainfall is about $1332 \mathrm{~mm}$. The mean annual minimum and maximum temperature of the area ranges between $20^{\circ} \mathrm{C}$ and $29^{\circ} \mathrm{C}$, respectively and the vegetation type was predominantly savannah wood land type. Data from Bench Maji Zone Livestock and fishery (BMZLFR) and other scholar indicated that, the inhabitants of the study area practice mixed agriculture, crop production and livestock rearing, about 49,967cattle, 8,681 shoats, 146 equines and 69,425 chickens were expected to exist in the area (BMZLFR, 2014; Belay, 2018).

Study animals: A total of 200 cattle (50 from each rural kebeles) were randomly selected from rural kebeles. All 
animals were treated with Diminazene aceturate at the recommended dose $(7 \mathrm{mg} / \mathrm{kg})$ of body weight to eliminate the existing trypanosome infection. From each rural kebeles, cattle were randomly divided in two groups (25 in ISMM treatment group and 25 in control group) following the methods proposed by Eisler et al. (2001). After 2 weeks of blanket treatment (day 0), one group were treated with isometamidium chloride at a recommended dose of $(1 \mathrm{mg} / \mathrm{kg})$ body weight and the other group were left untreated or control group.

\section{Study design}

Field Assessment of Isometamidium and Diminazene

Resistance: On the basis of results of previous prevalence study on trypanosomosis and guidelines of owner's and district veterinary professionals; four rural kebeles of the district were selected for ISMM block treatment study using purposive sampling methods. The studies conducted by Mizan Veterinary Laboratory Center confirmed that the area had high prevalence of trypanosomosis which was $28.5 \%$ (unpublished data, 2010) and the perception on trypanocidal drug's efficacy failure mentioned by interviewed livestock keepers and district professionals were suggestive for taking this proposed study in selected rural kebeles. Body weight of each animal were determined by using heart girth. An animal in each group were then examined for the presence of trypanosome infection by taking blood from ear vein using a heparinized capillary tube and examined under phase contrast microscope using buffy coat technique (Murray and Mcintyre, 1977). Sampling was conducted every two weeks starting from day of blanket treatment up to 8 weeks following ISMM block treatment i.e., day, $-14,0,+14,+28,+42$ and +56 . In each group, cattle found infected with trypanosomes were treated with diminazene aceturate at a recommended dose rate $(7 \mathrm{mg} / \mathrm{kg})$ body weight. Furthermore, PCV of each animal were measured using PCV reader instrument.

Parasitological Examination: Blood samples were collected from the ear veins of the study animals into heparinized capillary tubes. The collected samples were then examined by the capillary micro hematocrit centrifugation method to estimate the packed cell volume (PCV) followed by the buffy coat (BC) examination using phase contrast microscope for the detection of trypanosomes in the blood.

The identification of the species was ensured on the basis of a movement in wet films and Giemsa stained thin blood smear prepared from the trypanosome positive animals and examined under a microscope using the oil immersion (100×objective (Murray \& Mcintyre, 1977). Trypanosome species can be identified by the following morphological characteristics (Gemsen et al., 2003).

Table 1. Morphological characteristics of Trypanosome species.

\begin{tabular}{|c|c|c|c|c|c|c|}
\hline Species & $\begin{array}{c}\text { Site of } \\
\text { development } \\
\text { in tsetse fly }\end{array}$ & Free flagellum & kinetoplast & $\begin{array}{l}\text { Undulating } \\
\text { membrane }\end{array}$ & $\begin{array}{l}\text { Size in } \\
\text { micrometer }\end{array}$ & $\begin{array}{l}\text { Size and motility in wet } \\
\text { film }\end{array}$ \\
\hline T.vivax & Proboscis & present & $\begin{array}{l}\text { Large, } \\
\text { terminal }\end{array}$ & $\begin{array}{l}\text { Non } \\
\text { prominent }\end{array}$ & $20-26$ & $\begin{array}{l}\text { Large, extremely active } \\
\text { travels the whole field } \\
\text { very } \\
\text { quickly, pausing } \\
\text { occasionally }\end{array}$ \\
\hline T.brucei & $\begin{array}{l}\text { Mid-gut, } \\
\text { salivary gland }\end{array}$ & $\begin{array}{l}\text { Present in all } \\
\text { but not in } \\
\text { stumpy form }\end{array}$ & $\begin{array}{l}\text { Small, sub } \\
\text { terminal } \\
\text {, central }\end{array}$ & prominent & $15-35$ & $\begin{array}{l}\text { Large, rapid movement } \\
\text { in } \\
\text { confined areas }\end{array}$ \\
\hline T.congolense & $\begin{array}{l}\text { Mid-gut, } \\
\text { proboscis }\end{array}$ & Absent & $\begin{array}{l}\text { Medium, } \\
\text { sub } \\
\text { terminal, } \\
\text { marginal }\end{array}$ & $\begin{array}{l}\text { Not } \\
\text { prominent }\end{array}$ & $9-18$ & $\begin{array}{l}\text { Small, sluggish active, } \\
\text { adheres to red blood } \\
\text { cells by } \\
\text { anterior end }\end{array}$ \\
\hline
\end{tabular}

Data analysis: The collected data were coded and entered into a computer using Microsoft Office Excel 2007. In order to determine factors that can explain the variation in drug resistance, case control group was used. For field assessment of isometamidium and deminazene treatment failures, data were analyzed using Cox proportional hazard model which is commonly used for survival analysis. The efficacy of deminazene aceturate treatment was assessed on the basis of whether or not parasitaemia followed within 
two weeks after each treatment of any cattle on day 0 to 56. Interpretation of survival data was made following the methods used by Eisler et al. (2001). Terminated subjects were not included for the data analysis, and only those animals stayed until the end of the experimental period were considered. All the data collected were analyzed using Statistical Package for Social Sciences (SPSS).

\section{RESULTS AND DISCUSSION}

In the present study pertaining to the prevalence rate of trypanosome infection in both groups have been indicated in Table 2. In treated group, the experimental animals were diagnosed at blanket treatment [day i.e.
Day-14 and ISMM block treatment day (day, o)], the animals were found highly infected. The overall prevalence of trypanosome infection in control group was 76.8 and $23.2 \%$ in treated group. The overall prevalence of trypanosome species in cattle within the study kebeles for both treated and control groups were $71.7 \%, 64.4 \%, 41.7 \%$ and $57.8 \%$ in Otawa, Berji, Alenga and Semerta, respectively (Table 3). There was no statistical significant difference between the study kebeles $(\mathrm{P}>0.05)$. The prevalence of trypanosome infection was higher in control (76.8\%) than treated $23.2 \%$ animals but there was no statistically significant difference $(\mathrm{P}>0.05)$.

Table 2. Prevalence of Trypanosomiasis in Study area.

\begin{tabular}{lcccc}
\hline Study kebeles & Group & Sample size & No of positive & Prevalence (\%) \\
\hline Otawa & Control & 25 & 25 & 100 \\
& Treated & 21 & 8 & 38.1 \\
& Total & 46 & 33 & 71.7 \\
\hline Berji & Control & 22 & 18 & 81.8 \\
& Treated & 23 & 11 & 47.8 \\
& Total & 45 & 29 & 64.4 \\
\hline Alenga & Control & 25 & 12 & 48 \\
& Treated & 23 & 8 & 34.8 \\
& Total & 48 & 20 & 41.7 \\
\hline Semerta & Control & 23 & 18 & 78.3 \\
& Treated & 22 & 8 & 36.4 \\
& Total & 45 & 26 & 57.8 \\
\hline \multirow{2}{*}{ Overall } & Control & 95 & 73 & 76.8 \\
\hline X-2 testchi & Treated & 89 & 35 & 23.2 \\
\hline
\end{tabular}

$\mathrm{X}-2$ test chi-square test.

The proportion of trypanosome infection within specieslevel indicated that $13(76.5 \%)$ cattle were found to be infected by T.Congolense, $4(23.5 \%)$ cattle were found to be infected by $\mathrm{T}$. vivax as shown in Table 3 . The prevalence of trypanosome species showed there was no statistical differences ( $\mathrm{p}>0.05)$.

The 25\% survival time for the treatment and control groups of cattle in the study kebeles appeared 14 . The confidence interval varies between groups as shown in Table 4. The mean hazard rates of the treatment and control groups of cattle ranged from $0.17-0.51$ in both treated and control groups, across the study kebeles.

The hazard ratio of control to treatment groups of cattle were $3.14,1.68,1.5$ and 2.28 for Outawa, Berji,
Alenga and Semerta Kebeles (Table 5). In the present study, more than $25 \%$ of the animals at each study kebeles of the treatment group were found infected with trypanosome by day 56 (8th week) of the ISMM block treatment study. This indicates that there was a resistance against ISMM treatment by the trypanosome species. Thus, the probability to survive 8 weeks after the start of ISMM block treatment study varied among the studied rural kebeles and there was statistical significant difference between the rural kebeles. Kaplan-Meier survival estimates of the control and treatment groups at each rural kebele were significantly differed in control and treated group $(\mathrm{P}<$ 0.05 ) as shown in figure 1. 
Table 3. Ratio of trypanosome species infection in the study area.

\begin{tabular}{|c|c|c|c|c|c|}
\hline \multirow{2}{*}{ Study kebeles } & \multirow{2}{*}{ Group } & \multicolumn{2}{|c|}{ Trypanosome species } & \multirow{2}{*}{$\begin{array}{c}\mathrm{X}-2 \text { test Value } \\
0.678\end{array}$} & \multirow{2}{*}{$\frac{\text { P-value }}{0.878}$} \\
\hline & & T.Congolense & T.Vivax & & \\
\hline \multirow[t]{2}{*}{ Otawa } & Control & $21(35)$ & $3(23)$ & & \\
\hline & Treated & $7(22.3)$ & $1(25)$ & & \\
\hline \multirow[t]{2}{*}{ Berji } & Control & $15(25)$ & $3(23)$ & & \\
\hline & Treated & $9(29)$ & $2(50)$ & & \\
\hline \multirow[t]{2}{*}{ Alenga } & Control & $9(15)$ & $4(30.8)$ & & \\
\hline & Treated & $7(22.6)$ & $1(25)$ & & \\
\hline \multirow[t]{3}{*}{ Semerta } & Control & 15)25) & $3(23)$ & & \\
\hline & Treated & $8(25.8)$ & NR & & \\
\hline & Control & $60(66)$ & $13(76.5)$ & 0.726 & 0.394 \\
\hline Total & Treated & $31(34)$ & $4(23.5)$ & & \\
\hline
\end{tabular}

NR, Not Reported; Percent in parenthesis are percentage values.

Table 4. Mean hazard rate and 25\% survival time of control and treated groups of cattle up to day 56 of ISMM block treatment in the study areas.

\begin{tabular}{llccccc}
\hline \multirow{2}{*}{ SK } & Group & Sample size $\{\mathrm{a}\}$ & No of failures & $\begin{array}{c}\text { Time at risk } \\
\text { \{days }\}\end{array}$ & $\begin{array}{c}\text { Mean hazard } \\
\text { rate }\{\mathrm{b}\}\end{array}$ & $\begin{array}{c}25 \% \text { survival } \\
\text { time }\{\mathrm{c}\}\end{array}$ \\
\hline Otawa & Control & 25 & 25 & 56 & 0.44 & 14 \\
& Treated & 21 & 8 & 56 & 0.14 & 14 \\
& Total & 46 & 33 & 112 & 0.29 & 14 \\
\multirow{5}{*}{ Berji } & Control & 22 & 18 & 56 & 0.32 & 14 \\
& Treated & 23 & 11 & 56 & 0.19 & 14 \\
& Tlengal & 45 & 29 & 112 & 0.51 & 14 \\
& Control & 25 & 12 & 56 & 0.21 & 14 \\
& Treated & 23 & 8 & 56 & 0.14 & 14 \\
& Total & 48 & 20 & 112 & 0.17 & 14 \\
& Control & 23 & 18 & 56 & 0.32 & 14 \\
& Treated & 22 & 8 & 56 & 0.14 & 14 \\
& Total & 45 & 26 & 112 & 0.23 & 14 \\
\hline
\end{tabular}

SK, Study kebele; $a=$ total number of cattle presented at day 14 when the first case was diagnosed; $b=$ the number of cattle infected \{failure\} divided by total time at risk from day 0 to 56 day of ISMM block treatment; $c=$ time at which 25\% of the animal become parasitaemic as a result of trypanosomes.

Table 5. Hazard ratio and proportion of cattle with parastaemic in control and treatment groups of cattle up to day 56 of ISMM block treatment study in selected study kebeles.

\begin{tabular}{clcccccc}
\hline \multirow{2}{*}{ SK } & Group & $\begin{array}{c}\text { Sample } \\
\text { size }\{\mathrm{a}\}\end{array}$ & $\begin{array}{c}\text { No of } \\
\text { failures }\end{array}$ & $\begin{array}{c}\text { Time at } \\
\text { risk day }\end{array}$ & $\begin{array}{c}\text { Mean hazard } \\
\text { rate }\end{array}$ & $\begin{array}{c}\text { Hazard } \\
\text { ratio }\{\mathrm{b}\}\end{array}$ & $\begin{array}{c}\text { Proportion in } \\
\%\{\mathrm{c}\}\end{array}$ \\
\hline Otawa & Control & 25 & 25 & 56 & 0.44 & 3.14 & 1 \\
& Treated & 21 & 8 & 56 & 0.14 & & 0.38 \\
& Total & 46 & 33 & 112 & 0.29 & & 0.71 \\
\multirow{5}{*}{ Berji } & Control & 22 & 18 & 56 & 0.32 & 1.68 & 0.81 \\
& Treated & 23 & 11 & 56 & 0.19 & & 0.47 \\
& Total & 45 & 29 & 112 & 0.51 & & 0.64 \\
\multirow{5}{*}{ Alenga } & Control & 25 & 12 & 56 & 0.21 & 1.5 & 0.48 \\
& Treated & 23 & 8 & 56 & 0.14 & & 0.34 \\
\hline
\end{tabular}




\begin{tabular}{lllccccc}
\hline \multirow{3}{*}{ Semerta } & Total & 48 & 20 & 112 & 0.17 & \multirow{2}{*}{0.41} \\
& Control & 23 & 18 & 56 & 0.32 & 0.78 \\
& Treated & 22 & 8 & 56 & 0.14 & & 0.36 \\
& Total & 45 & 26 & 112 & 0.23 & & 0.57 \\
\hline
\end{tabular}

SK, Study kebele; a-total number of cattle presented at day 14 when the case was diagnosed; $b$, the ratio of mean hazard rate of control to treatment groups of cattle in ISMM block treatment study since day 0 up to day 56; $c$, the proportion of cattle becoming parasitaemic during 8 weeks period of ISMM block treatment study since day 0.

Kaplan-Meier survival estimates and statistical test for the equality of the survivor function of the control and treatment groups of cattle in the study area indicates, the infection of cattle with the trypanosome species was found in every fourteen days of blood test after ISMM treatment (Figure 1) indicating a resistance of trypanosome species for the treatment with diaminazine with the recommended dose of $(7 \mathrm{mg} / \mathrm{kg})$.

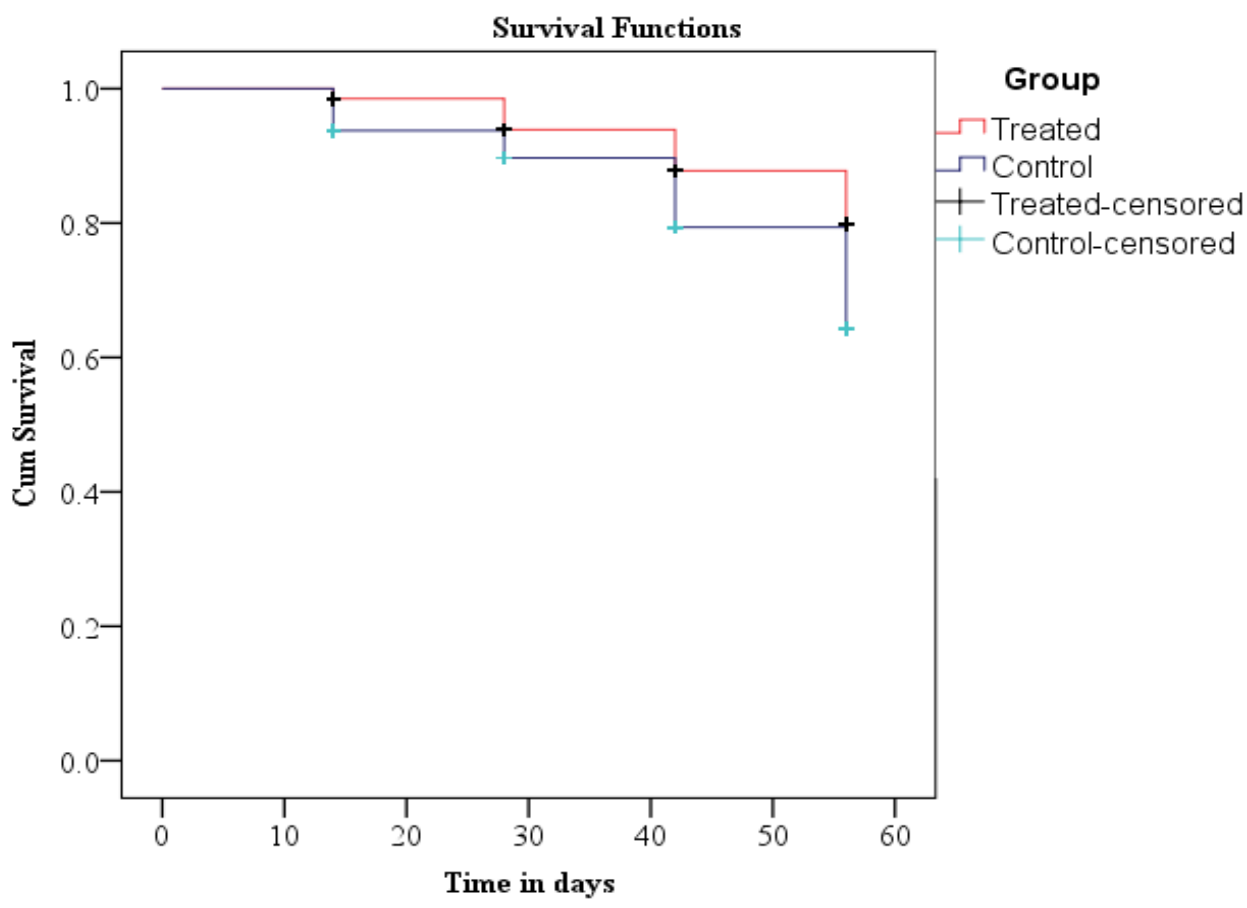

Figure 1. Resistance of trypanosome species for the treatment with diaminazine.

The present study revealed that from a total of 184 animals in the study area, $73(76.8 \%)$ in control and $35(23.2 \%)$ in treated group, were positive for trypanosomes. The previous study indicated that trypanosomiasis was also chronic problem in the study area with the prevalence of $42.2 \%$ in the Gureferda district (Yismashewa et al., 2017). This finding presented the prevalence of trypanosomes infection was very high. It was higher than with the reports of (Solomon \& Fitta, 2010; Teka et al., 2012) where they have reported the prevalence of $12.41 \%$ in Metekel and Awi Zones of Northwest Ethiopia and 4.43\% in Arbaminch Southern Ethiopia. The higher prevalence reported from Awi zone (Kebede et al., 2009) (10.1\%),
20.74\% from Metekel zones (Mekuria et al., 2012) and 4.4\% from Bench Maji Zone (Stein et al., 2011).

In addition, the prevalence reported from Wolayta and Dawero Zones was 20.40\% (Miruk et al., 2008) and in Northwest Ethiopia reported by Shimelis et al. (2017) was $21.5 \%$ which was comparable with the prevalence obtained from treated group in the present study. The relatively higher prevalence of trypanosomosis in this study may be related to tsetse distribution was very high which lead for the reinfection of animals. However, the prevalence rate obtained in the control group was $76.8 \%$ which was higher than the various reports in the country. This, might be due to the presence of high tsetse and other mechanical transmitting flies in the area. 
The present pilot study on trypanocidal drugs conducted in four selected kebeles of the district for a period of 56 days by comparing the two groups control and treated showed that, there was no statistical variation $(\mathrm{P}>0.05)$ in infection by trypanosomes between the two groups. During the study period from control groups 25,19,12 and 18 and from treated groups 12,11,8 and 9 animals where found positive for infection with trypanosomes species in the study kebeles of Otawa, Berji, Alenga and Semerta, respectively. In the present study the infection rate of T.congolense was $76.8 \%$ in control groups and $23.2 \%$ in treated groups. This results are in agreement with the reports in South West Ethiopia by Abebe \& Jobere (1996) with an infection rate of $58.5 \%$ for $\mathrm{T}$. congolense and $31.2 \%$ for T.vivax. T.congolense was the dominant parasite identified in the present study which was in similar scenario with reports obtained in tsetse infested areas of the country (Afework et al., 2000: Tewelde et al., 2004; Dagnachew et al., 2005). This might be attributed to the difference in tsetse apparent density in the study area.

The $25 \%$ survival time analysis showed that $25 \%$ of the control group of cattle becomes infected with trypanosome parasite at day 14 in all rural kebeles of the study period and the prophylactic effect of ISMM was found to be very low. In all kebeles more than $25 \%$ of the ISMM treated groups of cattle 12,11,8 and 9 animals in Otawa, Berji, Alenga and Semerta kebele, respectively were parasitemic in 8 weeks following ISMM block treatment and this suggest, that there was resistance of trypanosomes against ISMM. Resistance against drug was strongly suspected when more than $25 \%$ of ISMM treated cattle become parasitemic within 8 weeks of exposure (Eisler et al., 2001). According to Eisler et al. (2001) in areas with evidence of drug resistance on the grounds of the ISMM treated cattle becoming infected within 8 weeks of exposure, it may nevertheless be worth continuing prophylaxis in situation where the ratio of the mean hazard rate for control and treated herds over 8 weeks become greater than 2 . In the present study the mean hazard rate was 2.15 which was greater than 2. The Kaplan-mire survival curve was also in agreement with the results reported in the present findings. Repeated recurrence/relapse infections of trypanosomes were observed in some animals after treatment of diminazen aceturate with the recommended dosage before two weeks. Therefore, the recurrent infection might not be only due to new infections but also resistance strains might be detected (Rowland's et al., 2001; Shimelis et al., 2005). The comparisons of trypanosome incidence and recurrence infection in south west Ethiopia showed drug resistant trypanosomes against diminazen aceturate (Rowland's et al., 2001). Vitouley et al. (2012) indicated that under dosing, irregular use of prophylactics and discontinuation while at risk time and high incidence of trypanosomes are the root cause of development of drug resistance. Similarly, various scholars in Ethiopia have reported appearance of drug resistant trypanosomes in the Country (Mulugeta et al., 1997; Afework et al., 2000; Tewelde et al., 2004; Shimelis et al., 2008). There is increasing evidence that the efficacy of chemotherapy is becoming reduced by the widespread development of trypanosome drug resistance in various parts on the country (Van den Bossche et al., 2000; Delespaux et al., 2008). Recent reports confirmed that diminazene aceturate and isometamidium chloride resistance in $\mathrm{T}$. vivax and T. congolense in West Africa was observed (Sow et al., 2012; Vitouley et al., 2012). Even in Ethiopia the existence of drug resistant trypanosomes has also been reported by several authors (Mulugeta et al., 1997; Afework et al., 2000; Tewelde et al., 2004; Shimelis et al., 2008; Dagnachew et al., 2014). The present study showed that treatment with isometamidium to control trypanosome have developed resistance with the recommended dose of $(1 \mathrm{mg} / \mathrm{kg}$ of body weight). This might be due to higher frequency of treatment, under dosage and mishandling especially when the drugs are administered by farmers and possible occurrence of poor quality drugs on the market could be reasons for the development of resistance (Vitouley et al., 2012).

\section{CONCLUSION AND RECOMMENDATIONS}

In conclusion, the result showed that, trypanosomiasis was a major animal health problem in the tsetse infested areas of Bench Maji Zone, South Western, Ethiopia and trypanocidal drugs available in the area was exposed to risks of drug resistance under a recommended dose of ISMM $(1 \mathrm{mg} / \mathrm{kg}$ body weight). In the present study, the prevalence of trypanosome infection was very high. The identified trypanosome specie in the area predominantly T.congolense. However, T. congolense and T. vivax were species of trypanosomes responsible for the occurrence of trypanosomiasis in tsetse infested areas of Bench Maji Zone. Treatment of infected cattle with the recommend doses of trypanocides showed incomplete parasite clearance, consistent with the occurrence of resistant 
strains and adding to growing evidence that such resistance may be a problem in the control of trypanosomosis in the study area. Therefore, another drug should be investigated which can properly threat the disease and also better to conduct a combined effect of the available drugs as well as with relatively higher dose than the recommended level, so as to asure the available efficiency of drugs in tsetse infested areas of Guraferda District to reduce mortality and morbidity of cattle there by to benefit the farmers.

\section{CONFLICT OF INTEREST}

The authors declare that they have no competing interests.

\section{ACKNOWLEDGEMENTS}

The authors would like to acknowledge Bench Maji Zone, Guraferda District Livestock and Fishery development offices for their kind support and collaborative work. We are also grateful for Mizan Regional Veterinary Diagnostic Laboratory Center for providing diagnostic and laboratory equipment's and reagents. Finally, we are also indebted to thank those farmers and development agents who participated in this study.

\section{REFERENCES}

Abebe, G., Jobre, Y., (1996). Trypanosomiasis: a threat to cattle production in Ethiopia. Rèvue de Mèdecine Vètèrinarie, 147, 897-902.

Afework, Y., Clausen, P.H., Abebe, G., Tilahun, G. \& Mehlitz D. (2000). Multiple-drug resistant Trypanosoma congolense populations in village cattle of Metekel district, Northwest Ethiopia. Acta Trop. 76, 231-238.

Belay H., (2018). Drivers of Land Use/Land Cover Change in the Guraferda District of Bench Maji Zone, Southwestern Ethiopia. Research \& Reviews: Journal of Ecology and Environmental Sciences, 6(1), 52-62.

Codjia, V., Mulatu, W., Majiwa, P.A.O., Leak, S.G.A., Rowlands, G.J. \& Authie E. (1993). Epidemiology of bovine trypanosomosis in the Ghibe Valley Southwest Ethiopia: occurrence of populations of Trypanosoma congolense resistant to diminazene, isometamidium and homidium. Acta Trop. 53, 151-163.

Dagnachew, S., Sangwan, A.K. \& Abebe, G. (2005). Epidemiology of bovine trypanosomosis in the Abay (Blue Nile) basin areas of Northwest Ethiopia. Revue et Médecine Véterinarie, 58, 151-157.
Delespaux, V., Geysen, D., Van den Bossche, P. and Geerts, S. (2008). Molecular tools for the rapid detection of drug resistance in animal trypanosomes. Trends Parasitol. 24, 236-242.

Dereje A. \& T. Mossie. (2017). Prevalence of Bovine Trypanosomosis and Farmers' Perception of the Disease and Its Management in Guangua and Dangila Districts. Journal of Biology, Agriculture and Healthcare, 7(7),1-10.

Eisler, M. C., Brandt, J., Bauer, B., clausen, P.H., Delespaux, V., Holmes, P.H., Ilemobade, A.,Machila, N., Mbwambo, H., Mcdermott, J.,Mehlitz, D., Murilla, G., Ndung'u, J.M., Peregrine, A.S., Sidibe, I., Sinyangwet L. \& Geerts, S. (2001). Standardized tests in mice and cattle for detection of drug resistance in tsetse transmitted trypanosomes of Africa in domestic Cattle. Veterinary parasitology, 97, 171-183

Geerts, S., Delespaux, V., Brandt, J., Elyn, R. \& Eisler M. (2002). Monitoring the correct use of Isomethamedium by farmers and veterinary assistants in Eastern Province of Zambia using the Isomethamedium-ELISA. Vet. Parasitol., 110, 117-122.

Geysen D, Delespaux V. \& Geerts S. (2003). PCR-RFLP using Ssu-rDNA amplification as identification of animal trypanosomes; a review and perspectives. Vet Parasitology, 109, 213-231.

Ian, M., Peter H. \& Michael A. (2004).The Trypanosomosis. CABI publishing, 23, 431- 458.

John P. K., (2005). The trouble with trypanocidal drug. An easy of Pan African Tsetse and Trypanosomosis Eradication Campaign. Commission of the African Union. Addis Ababa, Ethiopia. P.7

Kebede, N. \& A. Animut, (2009). Trypanosomosis of cattle in selected districts of Awi zone, northwestern Ethiopia. Tropical Animal Health and Production, 41.1353-1356.

Mekuria, S. \& F. Gadissa, (2011). Survey on bovine trypanosomosis and its vector in Metekel and Awi zones of Northwest Ethiopia. Acta Tropica, 117, 146-151.

Miruk, A., Hagos, A., Yacob, H.T., Asnake, F. \& Basu, A.K. (2008). 'Prevalence of bovine trypanosomosis and trypanocidal drug sensitivity studies on Trypanosoma congolense in Wolyta and Dawero 
zones of southern Ethiopia', Veterinary Parasitology, 152, 141-147.

Mulugeta, W., Wilkes, J., Mulatu, W., Majiwa, P.A.O., Masake, R. \& Peregrine, A.S. (1997). Long-term occurrence of Trypanosoma congolense resistant to diminazene, Isometamidium and Homidium in cattle at Ghibe, Ethiopia. Acta Trop, 64, 205-217.

Murray M., Murray P.K. \& Mcintyre W.I.M. (1977). An improved parasitological technique for the diagnosis of African trypanosomosis. Trans. R. Soc. trop. Med. Hyg., 71, 325-326.

Rowlands G.J., Leak S.G.A., Peregrine A.S., Nagda S.M., Mulatu W. \& D'ieteren G.D.M. (2001). The incidence of new and the prevalence of recurrent trypanosome infection in cattle in Southwest Ethiopia exposed to a high challenge with drug resistant parasite. Acta trop., 79, 149163.

Selamawi, (2016). A cross-sectional study on the apparent density of tsetse flies and prevalence of bovine Trypanosomosis. Global Journal of Medicine and Surgery, 10(4), 151-155.

Shimelis Dagnachew, A.K. Sangwan and Getachew Abebe, (2005). Epidemiology of Bovine Trypanosomosis in the Abay (Blue Nile) Basin Areas of Northwest Ethiopia. Revue Élev. Méd. vét. Pays trop., 58(3), 151-157.

Shimelis Dagnachew, BiniamTsegaye, Addissu Awukew, Meseret Tilahun, Hagos Ashenafi, Tim Rowan, Getachew Abebe Dave J. Barry, Getachew Terefe and Bruno M. Goddeeris, (2017). Prevalence of bovine trypanosomosis and assessment of trypanocidal drug resistance in tsetse infested and non-tsetse infested areas of Northwest Ethiopia. Parasite Epidemiology and Control, 2, 0-49

Shimelis, D., Arun, K.S. \& Getachew, A. (2008). Assessment of trypanocidal drug resistance in cattle of the Abay (Blue Nile) Basin areas of Northwest Ethiopia. Ethiopian Veterinary Journal, 12, 45-59.

Shimels, D., Sangwan, A. \& Getachew, A. (2005). Epidemiology of bovine trypanosomosis in Abay (Blue Nile) basin areas of Northwest Ethiopia, Revue Élev. Méd. vét. Pays trop, 58, 151-157.

Simbarashe, C., Tanguy, M., Boniface, N., Peter, V., Jan V. \& Vincent, D., (2011). High prevalence of drug resistance in animal trypanosomes without a history of drug exposure, 5, 1454.

Solomon S., Y. Muktar \& D. Belina, (2016). A review on trypanocidal drug resistance in Ethiopia. Journal of Parasitology and Vector Biology,7(4), 58-66.

Solomon, M. \& Fitta, G., (2010). Survey on bovine trypanosomosis and its vector in Metekel and Awi Zones of North West Ethiopia, Acta Tropica. 117, 146-151.

Sow, A., Sidibé, I., Bengaly, Z., Marcotty, T. \& Séré, M. (2012). Field detection of resistance to isometamidiumchloride and diminazene aceturate in Trypanosoma vivax from the region of the Boucledu Mouhoun in Burkina Faso. Vet. Parasitol, 187, 105-111.

Stein, J., Ayalew, W., Rege, E. D., Mulatu, W., Lemecha, H., Tadesse, Y., \& Philipsson, J. (2011). Trypanosomosis and phenotypic features of four indigenous cattle breeds in an Ethiopian field study. Veterinary Parasitology, 178(1-2), 40-47.

Tatek D., B. Kidane, Z. Yilma \& B. Teshome. (2018). Farmers' perception towards farm level rubber tree planting: a case study from guraferda, south-western Ethiopia. Forestry Research and Engineering: Int., Journal, 2(4), 192-196.

Teka W., Terefe D. \& Wondimu A. (2012). Prevalence study of bovine trypanosomosis and tsetse density in selected villages of Arbaminch, Ethiopian, Journal of Veterinary Medicine and Animal Health, 4(3), 36-41.

Tewelde, N., Abebe, G., Eisler, M.C., McDermott, J., Greiner, M. and Afework, Y., (2004). Application of field methods to asses' isometamidium resistance of trypanosomes in cattle in western Ethiopia. Acta Trop, 90, 163-170.

Van den Bossche, P., Doran, M. \& Connor, R.J. (2000). An analysis of trypanocidal drug use in the Eastern Province of Zambia. Acta Trop, 75, 247-258.

Vitouley, H.S., Sidibe, I., Bengaly, Z., Marcotty, T., Van Den Abbeele, J. \& Delespaux, V. (2012). Is trypanocidal drug resistance a threat for livestock health and production in endemic areas? Food for thoughts from Sahelian goats infected by Trypanosoma vivax in Bobo Dioulasso (Burkina Faso). Vet. Parasitol, 190, 349-354.

Yismashewa, W., Ayele, W., Dugasa O., Melaku A., Tigist K., Senait, G. \& Getachew D. (2017). Epidemiological Study of Cattle Trypanosomiasis 
in Southern Nations, Nationalities and Peoples Regional State, Ethiopia: Prevalence and Its Vector Density. European Journal of Biological Sciences, 9(1), 35-42.
Zeleke, G. (2011). Preliminary survey on tsetse flies and trypanosomosis at grazing fields and villages in and around the Nech Sar National Park, Southern Ethiopia. Ethiop, Vet Journal, 15, 59-6.

(a) (1) 